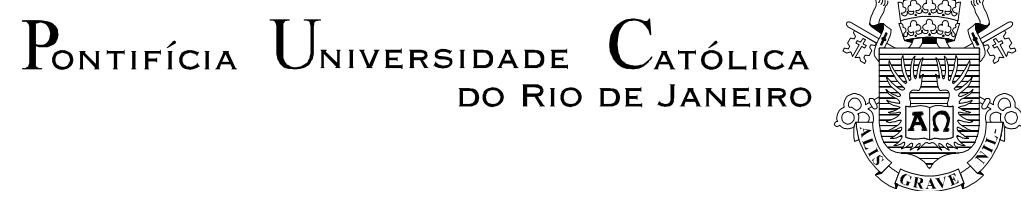

Catiane de Araujo Pimentel

\title{
Passado presente - lendo Pedro Nava no século XXI
}

\author{
Dissertação de Mestrado
}

\section{DEPARTAMENTO DE LETRAS \\ Programa de Pós-Graduação em Letras}

Rio de Janeiro, 13 de abril de 2010 


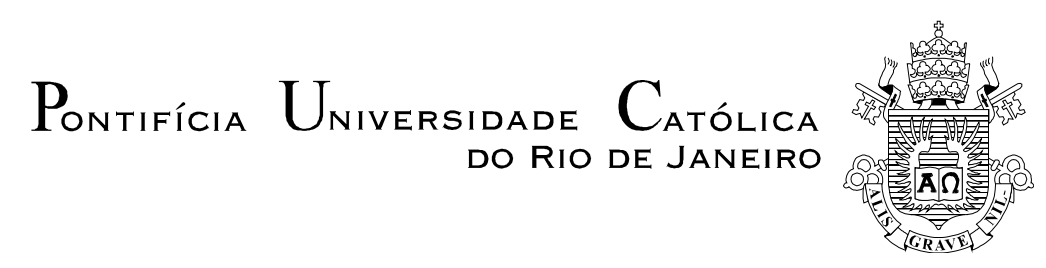

Catiane de Araujo Pimentel

\author{
PASSADO PRESENTE \\ Lendo Pedro Nava no Século XXI
}

\begin{abstract}
Dissertação de Mestrado
Dissertação apresentada como requisito parcial para obtenção do grau de Mestre pelo programa de Pós-Graduação em Letras do Departamento de Letras do Centro de Teologia e Ciências Humanas da PUC-Rio.
\end{abstract}

Orientadora: Marilia Rothier Cardoso

Rio de Janeiro

Abril de 2010 


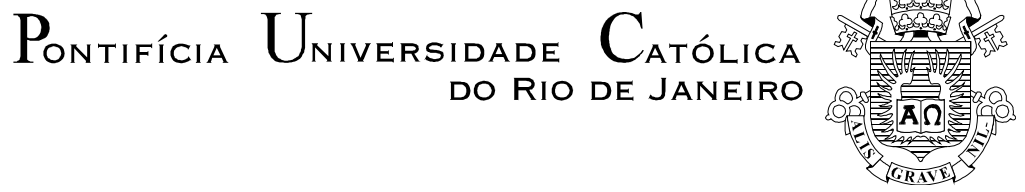

\title{
Catiane de Araujo Pimentel
}

\author{
PASSADO PRESENTE \\ Lendo Pedro Nava no Século XXI
}

\begin{abstract}
Dissertação apresentada como requisito parcial para obtenção do grau de Mestre pelo programa de Pós-Graduação em Letras do Departamento de Letras do Centro de Teologia e Ciências Humanas da PUC-Rio. Aprovada pela Comissão Examinadora abaixo assinada.
\end{abstract}

Profa. Marília Rothier Cardoso
Orientadora

Profa. Daniela Gianna Claudia B. Versiani

Pesquisador Visitante

Departamento de Letras - PUC-Rio

Prof. Luiz Antonio Silva

UERJ

Prof. Paulo Fernando Carneiro de Andrade

Coordenador Setorial do Centro de Teologia

e Ciências Humanas - PUC-Rio

Rio de Janeiro, 13 de abril de 2010. 
Todos os direitos reservados. É proibida a reprodução total ou parcial do trabalho sem autorização da universidade, da autora e da orientadora.

\section{Catiane de Araujo Pimentel}

Graduou-se em Letras - Português Literatura na UERJ (Universidade do Estado do Rio de Janeiro) em 2004. Participou de diversos fóruns e seminários nas áreas de linguistica, língua portuguesa e literatura brasileira.

Ficha Catalográfica

Pimentel, Catiane de Araujo

Passado presente: lendo Pedro Nava no Século XXI / Catiane de Araujo Pimentel; orientadora: Marilia Rothier Cardoso. - 2010.

88 f. ; $29,7 \mathrm{~cm}$

Dissertação (mestrado)-Pontifícia Universidade Católica do Rio de Janeiro, Departamento de Letras, 2010.

Inclui referências bibliográficas

1. Letras-Teses. 2. Leitura. 3. Memória. 4. Pedro Nava. 5. Linguagem sensorial. 6. Produção de presença. 7. Produção de sentido. I. Cardoso, Marilia Rothier. II. Pontifícia Universidade Católica do Rio de Janeiro. Departamento de Letras. III. Título.

CDD: 800 


\section{Agradecimentos}

A minha mãe, o anjo de bondade, que Deus escolheu para mim, com a magia de fascinar tudo quanto a rodeia e, sobretudo iluminar minha vida; amiga em todos os momentos, não vê limites para me auxiliar na realização dos meus objetivos e para me dar o direito de viver, desfrutando plenamente do melhor que a vida pode oferecer.

Ao meu pai, pela amizade, companheirismo, pelo intenso apoio e carinho ao longo da vida, pela preciosa ajuda, extrema dedicação e zelo, sem os quais esse trabalho não poderia ter sido realizado.

A minha orientadora, professora Marília Rothier Cardoso, por me conceder a oportunidade e o prazer de ser sua orientanda, acreditando no meu potencial, pela confiança, atenção, estímulo e parceria na realização do trabalho.

A professora Daniela Versiani, pela disponibilidade de tempo para me orientar na pesquisa supervisionada, pela paciência, atenção e apoio na pesquisa e no encaminhamento do trabalho, com contribuições muito valiosas à fundamentação teóricocrítica da dissertação.

Aos professores que, de bom grado se disponibilizaram a participar da Comissão examinadora.

Ao CNPq e à PUC-Rio, pelos auxílios concedidos. 


\section{Resumo}

Pimentel, Catiane de Araujo; Rothier, Marília Cardoso. Passado presente lendo Pedro Nava no Século XXI. Rio de Janeiro, 2010. 88p. Dissertação de Mestrado - Departamento de Letras, Pontifícia Universidade Católica do Rio de Janeiro.

O presente trabalho propõe uma perspectiva de leitura, em vertente contemporânea, das memórias de Pedro Nava, a partir das propostas teóricocríticas formuladas por Paul Zumthor, Susan Sontag e, em especial, Hans Ulrich Gumbrecht. O conceito de "produção de presença", cunhado por este estudioso, serviu como ponto de partida para a análise da construção da escrita naviana, que se concentrou, em particular, no $2^{\circ}$ volume das memórias, Balão Cativo, onde, tratando-se da passagem da infância à adolescência, enfatiza-se a formação do memorialista como leitor contumaz. Determinou-se enfocar o texto pelo prisma da leitura de jovens e adolescentes de hoje, destacando seus hábitos característicos. Esse perfil de leitor foi confrontado com as peculiaridades que identificam a autora da dissertação como leitora também jovem. As múltiplas vozes que interpenetram o caminho de leitura da mesma foram responsáveis pela escolha do objeto de pesquisa. Por sua potência de "produzir presença", a escrita de Nava incentiva o abandono da leitura passiva, pois possibilita uma participação perceptivo-intelectual na narrativa, permitindo aproximar as experiências de leitura, peculiares à autora, das práticas interativas de seus contemporâneos. Por essa vertente, o estudo crítico das estratégias concretizadoras empregadas na construção textual de Nava constitui o cerne do trabalho.

\section{Palavras-chave}

Leitura; memória; Pedro Nava; linguagem sensorial; produção de presença; produção de sentido. 


\section{Abstract}

Pimentel, Catiane de Araujo; Rothier, Marília Cardoso (Advisor). Past present - reading Pedro Nava in the 21st Century. Rio de Janeiro, 2010. 88p. MSc. Dissertation - Departamento de Letras, Pontifícia Universidade Católica do Rio de Janeiro.

This paper proposes a reading perspective, in a contemporary view, of the memories of Pedro Nava, from the theoretical-critical proposals as developed by Paul Zumthor, Susan Sontag and especially Hans Ulrich Gumbrecht. The concept of "presence production", as created by this scholar, served as the bottom line for the analysis of the navian writing construction, which focused, in particular, on the $2^{\text {nd }}$ volume of the memories, Balão Cativo, where, being the passage from childhood to adolescence, the formation of the author of the memories as an obstinate reader is emphasized. The focus of the text has been given under the reading point of view of youngsters and adolescents of today, pointing out their characteristic habits. This reader's profile has been confronted with the peculiarities identifying the author of the dissertation as a reader who is also young. The multiple voices that interpenetrate her way of reading were responsible for the choice of the research object. Due to its potentiality to "produce presence", Nava's writing stimulates the abandonment of the passive reading, for he enables a perceptive-intellectual participation in the narrative, allowing the reading experiences to become closer, in a peculiar way to the author, to the interactive practices of the contemporaries. Under this view, the critical study of the materializing strategies used in Nava's text construction constituted the core of the paper.

\section{Keywords}

Reading; memory; Pedro Nava; sensorial language; presence production; sense production. 


\section{Sumário}

1. Leitores do Século XXI 8

1.1. Minhas experiências de leitura 8

1.2. Dois perfis diferenciados de leitores 13

1.3. Delineando o perfil dos possíveis leitores das Memórias navianas 17

2. Nava: Uma leitura diferenciada 20

2.1. Uma leitora e sua escolha de um caminho teórico 20

2.2. Uma experiência peculiar 22

2.3. Memórias navianas: nova perspectiva de leitura 35

3. Uma viagem sensório-crítica ao passado 47

3.1. Nava: um percurso crítico re-presentificado 47

3.2. As marcas da primeira infância $\quad 51$

3.3. Saberes e sabores de um novo mundo 64

3.4. Marchando na Memória: O percurso do leitor para a maturidade 76

4. Referências bibliográficas 88 